Kathleen Joy B. Santiago, MD

Rodante A. Roldan, MD

Samantha S. Castañeda, MD

Department of Otorhinolaryngology

Head and Neck Surgery

Rizal Medical Center
Correspondence: Dr. Kathleen Joy B. Santiago

Department of Otorhinolaryngology

Head and Neck Surgery

Rizal Medical Center

Pasig Boulevard

Barangay Pineda, Pasig City 1603

Philippines

Phone: (632) 871 6269/ (0917) 8801082

Email:ent.hns_rmc@yahoo.com

Reprints will not be available from the author.

The authors declared that this represents original material that is not being considered for publication or has not been published or accepted for publication elsewhere in full or in part, in print or electronic media; that the manuscript has been read and approved by the authors, that the requirements for authorship have been met by the authors, and that the authors believe that the manuscript represents honest work.

Disclosures: The authors signed disclosures that there are no financial or other (including personal) relationships, intellectual passion, political or religious beliefs, and institutional affiliations that might lead to a conflict of interest.

Presented at the Philippine Society of Otolaryngology Head and Neck Surgery Analytical Research Contest. October 23, 2014. Unilab Bayanihan Center, Pasig City.

\section{Accuracy of Fine Needle Aspiration Biopsy in Diagnosing Parotid Gland Malignancy}

\author{
ABSTRACT \\ Objective: To determine the sensitivity, specificity, positive predictive value, negative predictive \\ value and overall accuracy of FNAB in detecting parotid malignancies in our institution.

\section{Methods:} \\ Design: Retrospective Chart Review \\ Setting: $\quad$ Tertiary Government Hospital \\ Participants: Postoperative records of seventy six (76) patients with tumors of the \\ parotid gland preoperatively diagnosed by FNAB.
}

Results: The sensitivity of FNAB was $46 \%$. The specificity and positive predictive value were both $100 \%$ and negative predictive value was $90 \%$. Overall accuracy in diagnosing malignant parotid tumor was $91 \%$.

Conclusion: FNAB in this institution is a poor predictor of malignancy, having a sensitivity rate of only $46 \%$. While this may serve as a basis for not recommending pre-operative FNAB for patients with parotid tumors in the interim, other factors should also be considered, including concerns with the actual performance and interpretion of FNAB in our institution.

Keywords: Parotid neoplasm, Cancer of the parotid, fine needle aspiration biopsy, sensitivity, specificity, accuracy

The role of Fine Needle Aspiration Biopsy (FNAB) in the workup of salivary gland tumors has been debated. In the 2016 National Comprehensive Cancer Network (NCCN) guideline, ${ }^{1}$ and in our institution, FNAB is a required diagnostic procedure to determine treatment and management of parotid gland tumors. However, some clinicians question its value. ${ }^{2}$

Supporters of the procedure noted that it offers helpful information for planning surgery and counselling patients regarding expectations from the surgery and its after care. ${ }^{3}$ Detractors, however, state that the management does not change regardless of the result of FNAB, believe that it may not be cost effective in routine cytology workup in every patient, and may do no more than increase the cost of healthcare. ${ }^{2}$

This paper aims to determine the sensitivity, specificity, positive predictive value, negative predictive value and overall accuracy of FNAB in detecting parotid malignancies in our institution. 


\section{METHODS}

With IRB approval, a retrospective review of medical records of patients who underwent parotidectomy in the Department of Otolaryngology-Head and Neck Surgery and the Department of Surgery of a single tertiary government hospital from January 2008 to August 2014 was done.

Records of all parotid surgeries performed during this period were screened for those that had both FNAB and surgical histopathology performed in this institution. An inflammatory result, records of cases where FNAB was performed in other institutions and where surgical histopathology results were unavailable were excluded. Only records with FNAB results of benign or malignant were included in the study. Non-diagnostic FNAB results were excluded.

In our institution, the standard procedure for fine needle aspiration biopsy was performed routinely by second year residents who had undergone training in the Department of Pathology, and results were interpreted by board-certified pathologists, who also interpreted final histopathologic results. Initial FNAB interpretation and final histopathologic interpretation were not usually performed by the same pathologist.

The final histopathology results were compared with the preoperative cytologic interpretation of the FNAB specimens. Sensitivity, specificity, positive predictive value (PPV), negative predictive value (NPV), and overall accuracy of FNAB to differentiate between benign and malignant disease were determined using the Galen and Gambino method. ${ }^{4}$

\section{The following parameters were analyzed:}

1. Sensitivity - the proportion of patients with malignant cytopathology and surgical histopathology results.

2. Specificity - the proportion of patients with benign cytopathology and surgical histopathology results.

3. Positive predictive value (PPV) - the probability of having a malignant surgical histopathology and malignant cytopathology findings.

4. Negative predictive value (NPV) - the probability of having a benign surgical histopathology with benign cytopathology findings.

5. Accuracy -the proportion of correct results (true positive and true negative) in relation to all cases studied.

\section{RESULTS}

A total of 94 records of patients who underwent parotidectomy in our institution were reviewed, and 76 records that had both final histopathologic results and preoperative FNAB performed in our institution were included. Eighteen records were excluded, either due to unavailable final histopathologic results or where FNAB had been performed elsewhere.

Of the 76 records that satisfied inclusion criteria, six (6) were reported malignant after FNAB and confirmed malignant on surgical histopathology (true positive). No cases were reported malignant on FNAB and later found to be benign on surgical histopathology (false positive). There were seven (7) cases that were reported benign on FNAB but were later found to be malignant on surgical histopathology (false negative). There were 63 cases that were reported benign on FNAB and confirmed benign on surgical histopathology (true negative). (Table 1)

Table 1. Comparison of FNA and Surgical Histopathology findings

\begin{tabular}{|l|c|c|c|}
\multicolumn{1}{|c|}{ FNA } & \multicolumn{2}{|c|}{ Surgical Histopathology } & Total \\
\hline & Malignant & Benign & \\
\hline Malignant & 6 & 0 & 6 \\
\hline Benign & 7 & 63 & 70 \\
\hline Total & 13 & 63 & 76 \\
\hline
\end{tabular}

There was a $46 \%$ sensitivity, $100 \%$ specificity, $100 \%$ positive predictive value, $90 \%$ negative predictive value, and $91 \%$ overall accuracy for FNAB in diagnosing parotid tumors in our sample.

\section{DISCUSSION}

The objective of this paper was to evaluate the accuracy of fine needle aspiration biopsy as a screening tool for parotid gland malignancies in terms of sensitivity, specificity, positive predictive value and negative predictive value. In this series, the probability that a tumor found to be malignant on FNAB would be malignant on surgical histopathology was $100 \%$ and the probability that a tumor found to be benign on FNAB would be benign on surgical histopathology was $90 \%$. These findings are similar with previous studies, with sensitivities and specificities ranging from $64 \%$ to $95 \%$ and $86 \%$ to $99 \%$, respectively.

Benign diseases were accurately diagnosed by FNAB with very low false positive rates as seen in this study. The most commonly diagnosed histology type was pleomorphic adenoma followed by Warthin's tumor.

The low sensitivity (46\%) result in this study can be attributed to its high false negative rate for the diagnosis of malignancy, as malignant tumors were falsely classified as benign. These results were also seen in the study of Fakhry et al. with $8 \%$ to $46 \%$ of cases. ${ }^{9}$ The implication 
of this result is that if FNAB had been used as a screening tool, 54\% of malignant lesions would have been missed. Many clinicians believe this could be related to technical factors and expertise of the cytopathologist. ${ }^{10}$ Most of the studies reviewed attribute false negative rates to sampling errors. ${ }^{10-12}$

According to a 2005 review, $^{13}$ the malignant neoplasm cases of salivary gland with the highest false negative rates were mucoepidermoid carcinoma, acinic cell carcinoma, and adenoid cystic carcinoma. These were the seven malignancies that were falsely diagnosed to be benign by FNAB in this study, with four (4) cases of mucoepidermoid carcinoma and one (1) case of acinic cell carcinoma diagnosed as pleomorphic adenoma and two (2) cases of adenoid cystic carcinoma diagnosed as trichoblastoma and pleomorphic adenoma respectively. Possible reasons for the discrepancies include the wide variability of benign and malignant tumors having similar cytologic features with differences in some cases being quantitative rather than qualitative; and the nature of FNAB, which is focused on cytology instead of histology. The morphologic patterns of salivary gland tumors contrast with the small size of the needle aspiration sample, which may not be representative of the entire mass. ${ }^{6,10}$

It is important to be able to characterize the tumor preoperatively in order to correctly inform the patient about the type of surgery that will be performed, the need for lymph node dissection, and the possibility of nerve sacrifice $^{7}$ as well as for psychological and medicolegal purposes. 5,7

However, although FNAB in this institution can accurately diagnose benign parotid tumors with a specificity rate of $100 \%$, it does not exclude malignancy because of a $54 \%$ false negative rate, and is a poor predictor of malignancy, having a sensitivity rate of only $46 \%$. Although this study is limited by small sample size and incomplete data, it may serve as a basis for recommending discontinuation of routine preoperative FNAB for parotid tumors in the interim, while other factors are considered, including concerns with the actual performance and interpretion of FNAB in our institution. The possible variability in levels of expertise both in obtaining specimens, and in FNAB interpretation should be addressed, and investigation into, and improvement of both FNAB specimen collection and interpretation may be in order.

\section{REFERENCES}

1. Network NCC. NCCN Clinical Practice Guidelines in Oncology. 2016 [updated 2016 May 6; cited 2016 Oct 7]; 1.2016: Available from: https://www.nccn.org/store/login/login aspx?ReturnURL=https://www.nccn.org/professionals/physician_gls/pdf/head-and-neck.pdf.

2. Batsakis JG, Sneige N, el-Naggar AK. Fine-needle aspiration of salivary glands: its utility and tissue effects. Ann Otol Rhinol Laryngol. 1992;101(2 Pt 1):185-8. Epub 1992/02/01. PubMed PMID: 1739267.

3. Nguansangiam S, Jesdapatarakul S, Dhanarak N, Sosrisakorn K. Accuracy of fine needle aspiration cytology of salivary gland lesions: routine diagnostic experience in Bangkok, Thailand. Asian Pac J Cancer Prev. 2012;13(4):1583-1588. PubMed PMID: 22799371.

4. Galen RS, Gambino SR. Beyond normality-the predictive value and efficiency of medical diagnosis. New York: NY:Wiley; 1975. p. 10-40.

5. Ali NS, Akhtar S, Juanid M, Awan S, Aftab K. Diagnostic accuracy of fine needle aspiration cytology in parotid lesions. SRN Surg. 2011 May;2011:721525. DOI: 10.5402/2011/721525. PubMed PMID: 22084773. PubMed Central PMCID: PMC3200214.

6. Tan LG, Khoo ML. Accuracy of fine needle aspiration cytology and frozen section histopathology for lesions of the major salivary glands. Ann Acad Med Singapore. 2006 Apr;35(4):242-8. PubMed PMID: 16710494.

7. Awan MS, Ahmad Z. Diagnostic value of fine needle aspiration cytology in parotid tumors. JPak Med Assoc. 2004 Dec;54(12):617-9. PubMed PMID: 16104489.

8. Cruz RM. The accuracy of fine needle aspiration biopsy in diagnosing malignancy of major salivary gland tumors. Philipp J Otolaryngol Head and Neck Surg. 2004 Jul-Dec;19(3-4):132-136

9. Fakhry N, Antonini F, Michel J, Penicaud M, Mancini J, Lagier A, et al. Fine-needle aspiration cytology in the management of parotid masses: Evaluation of 249 patients. Eur Ann Otorhinolaryngol Head Neck Dis. 2012 Jun;129(3):131-135. DOI: 10.1016/j.anorl.2011.10.008. PubMed PMID: 22626640.

10. Cohen EG, Patel SG, Lin O, Boyle JO, Kraus DH, Singh B, et al. Fine - needle aspiration biopsy of salivary gland lesions in a selected patient population. Arch Otolaryngol Head Neck Surg. 2004 Jun;130(6):773-778. DOI: 10.1001/archotol.130.6.773. PubMed PMID: 15210562.

11. Zurrida S, Alasio L, Tradati N, Bartoli C, Chiesa F, Pilotti S. Fine-needle aspiration of parotid masses. Cancer. 1993 Oct 15;72(8):2306-2311. PubMed PMID: 8402443.

12. Tryggvason T, Gailey MP, Hulstein SL, Karnell LH, Hoffman HT, Funk GF, et al. Accuracy of fineneedle aspiration and imaging in the preoperative workup of salivary gland mass lesions treated surgically. Laryngoscope. 2013 Jan;123(1):158-163. DOI: 10.1002/lary.23613. PubMed PMID: 22991236.

13. Hughes $\mathrm{JH}$, Volk EE, Wilbur DC. Pitfalls in salivary gland fine-needle aspiration cytology: lessons from the College of American Pathologists Interlaboratory Comparison Program in Nongynecologic Cytology. Arch Pathol Lab Med. 2005;129(1):26-31. Epub 2005/01/05. DOI: 10.1043/1543-2165(2005)129<26.PISGFC >2.0.CO;2. PubMed PMID: 15628905. 